\title{
Developing reading skills and motivation through mobile phones
}

\author{
Jasminka Pernjek \\ High school Krapina / Postgraduate study in glottodidactics, Faculty of \\ Humanities and Social Sciences, University of Zagreb \\ Šetalište hrvatskog narodnog preporoda 6, Krapina, Croatia \\ jpernjek@gmail.com \\ Monika Habjanec \\ High school Krapina / Polytechnic Croatian Zagorje Krapina \\ Šetalište hrvatskog narodnog preporoda 6, Krapina, Croatia \\ monika.habjanec@gmail.com
}

\section{Summary}

Continuous development of information and communication technologies has opened the door to a wide range of opportunities for digital learning. Recent didactic concepts, such as student-centered teaching stress the need for learner autonomy, which includes non-formal learning aided by modern technologies such as cell phones. Mobile phones have become an essential part of the teenager's life. If incorporated in the learning process, they could have a positive effect on student's motivation, which in turn would lead to improved achievements. The aim of this study was to determine the attitudes of Croatian students of English and German towards the use of modern technologies in teaching foreign languages. The study evaluates the students' attitudes towards reading comprehension in a foreign language when using traditional methods (multiple choice questions and paper-pencil C-Test method) as opposed to solving tasks with the use of mobile technology. The results of the study show that, although students find online testing more interesting and less stressful, they still prefer to be tested in the classical way.

Keywords: m-learning, Computer-Assisted Language Learning, Learner Perceptions, Learning Experiences

\section{Introduction}

Continuous development of information and communication technologies has opened the door to a wide range of opportunities for digital learning. Recent didactic concepts, such as student-centered teaching, involving a focus on both the interests and the needs of students, and learner autonomy, involving a focus on students' responsibility for their own learning, have created space for the 
incorporation of non-formal and informal learning and the use of modern technologies in the classroom discourse.

Non-formal and informal education, which is defined as any relatively structured learning outside of the educational system, contributes significantly to the enrichment of the learning experience, as recognized by the European Commission in the White Paper from November 1995 (224). This document clearly draws attention to the importance of the competences acquired outside of the formal education institutions, with a view to, among other things, facilitating the recognition of rich experiential knowledge and practical skills and incorporating that knowledge and skills in the concept of lifelong learning. With the purpose of fostering non-formal learning, education institutions have assumed new responsibilities, e.g. to enable the acquisition of knowledge in real life situations through projects, out-of-school activities aimed at the exploration of the immediate environment, involvement of experts and practitioners into teaching, introduction of students to the principles of learning autonomy and self-regulated learning, involving independent research and collection of information as well as a critical review and presentation of the results. A study on non-formal learning conducted by the German Youth Institute (Deutches Jugendinstitut, DJI) has revealed a significant difference between formal and informal learning with respect to the acquired content (Lipinski, 2000). The relevance to one's life and experience makes informal learning much more appealing than learning for the sake of learning, which is far too often the case in formal education. Informal learning is not a process regulated by a teacher, but rather a situational process regulated by the student. Therefore, information communications technologies, which provide access to any content at any given time, have become very important in this context.

A good example of an opportunity for informal learning is the use of computers and mobile phones. Mobile phones have become an essential part of the teenager's life. If incorporated in the learning process, they could have a positive effect on student's motivation, which in turn would lead to improved achievements. The role of an instant feedback should also not be neglected. The mlearning opportunities have been discussed for a long time. However, whereas ten years ago the central question was how to make certain contents available on mobile phones, the discussion today is aimed at the integration and orchestration of mobile technologies into the models supporting ubiquitous learning.

\section{Theoretical Background}

M-learning is a term derived from e-learning. It refers to any learning with the help of portable media, such as Smart Devices, by using Apps for learning on mobile phones, taking place at any time and any location. O'Malley et al. (2003) define e-learning as any type of learning that occurs when the student is not at a fixed, predetermined location or any learning involving the utilisation of learning opportunities provided by mobile technology. M-learning is a type of u- 
learning which Sakamura et al. (in Roreger and Schmidt, 2012) defines as a learning style treating learning as a process that takes place anywhere and anytime with the help of ubiquitous computing, allowing adaptability to different contexts so the size and the content of teaching learning unit can be adapted to the learner. Petrova and $\mathrm{Li}$ (2009) define mLearning as an ubiquitous learning activity supported by the appropriate mobile technology and pedagogical approach.The difference between m-learning and u-learning presents itself in the fact that $\mathrm{u}$-learning provides the learning material matching the situation which the learner is in.

An advantage of m-learning is the fact we can learn at any given time and at any place. However, due to technical restrictions it requires a good didactic preparation of material intended for m-learning which involves breaking down the learning content into small chunks (nuggets) which makes them ideal for, e.g. learning vocabulary.

Roreger and Schmidt (2012) put an accent on information exchange and group interviews as the basic mechanisms of active learning process, which are mainly intrinsically motivated and spontaneous. Creating groups on social networks associated with a given content element has a significant potential for successful distance learning. Since mobile devices are today used as a natural means of communication and entertainment, and their users have adopted the concept of constant presence, availability and access of the information on the Internet, they replace the traditional knowledge acquisition and memorization of information so it can be invoked and used in the future with the paradigm of the acquisition of skills to access the information constantly available on the Internet. Modern teaching methods also show a positive attitude towards mobile learning. The Situated Learning Theory (SLT - Collins, Brown \& Newman, 1989; Burston, 2011) states that the best type of learning is the one that occurs unintentionally and takes place during authentic activities, context and culture. While it is still perhaps too early to assess the effectiveness of utilization of mobile phones for learning, the didactic concept of student-centered learning undoubtedly constitutes a solid foundation for the development of a mobile learning program.

Mobile learning is a didactic reaction to a change in the learning habits and in the media competences of children and youth, to whom mobile phone is a ubiquitous communication device that offers access to a variety of media as well as a variety of didactic and scientific content. Although m-Learning brings a number of challenges to the educational environment, integrating mobile phones into school teaching and developing new forms of learning could be a motivating factor which would in turn have positive effects on other types of learning. Additionally, mobile learning is a contribution towards the growing significance of informal, ubiquitous learning taking place outside of school. The stages of learning that are moderated by the teacher can be interchanged with the stages 
of mobile-supported activities (e.g. the use of dictionaries, searching databases available on the Internet, making short video films, etc.).

\section{Previous research}

According to Heift and Chapelle (2012), the idea of using the possibilities offered by technology in language teaching has been around since the 1960s, initially focusing on enhancing the learning process with the use of computer-assisted instruction, while today's research focuses mainly on determining what, why, how and to what extent do new technologies lead to successful learning outcomes. Over the years, computer-assisted language learning (CALL) has developed on the principles of communicative language teaching. It is believed that with the use of CALL students develop learning strategies and improve their intercultural competence by using dictionaries, reading newspapers, watching contents on YouTube, and engaging in online forums. A rapid development of technology has made learning possible at any time and in any place (u-learning). The use of appropriate learning strategies and the development of effective learning activities have a crucial role in the context of CALL. A study conducted by Jung (2014) provided an insight into the views and expectations of English language learners (ELL) with respect to u-learning, showing a significant effect that u-learning has on the learner's motivation.

The development of educational technology offers possibilities for autonomous learning as a supplement to conventional classroom learning by enabling students to use many sources of information for independent learning and helping students take responsibility for learning by encouraging them to look for appropriate material and plan their own progress. The use of online communication technology allows a higher degree of independence in learning a foreign language because students can maximize their opportunities for practice.

Mobile phones are increasingly used in learning vocabulary, grammar and developing speaking and listening skills, as shown by a number of studies. The results indicate that mobile phones could provide an alternative source for learning vocabulary (Chen \& Chung, 2008; Hu, 2013; Lu, 2008; Stockwell, 2010). In one study (Lu, 2008) students were required to learn two sets of words by the use of mobile phones or in a traditional way, on paper. The students who studied using text messages showed a better understanding of vocabulary than those who were presented with the vocabulary on paper. Liaw (2006) shows that e-learning is not restricted only to learning vocabulary, but can also be applied in other learning contexts, e.g. to enhance intercultural competence by reading about your culture and sharing the new findings with speakers of another culture.

Adapting to the use of digital interfaces also means that the modes of learning and the perception of classroom material is changing, with smaller tasks, such as mini-essays and grammar quizzes becoming more suitable for a better learning experience with the use of mobile phones. Krashen (1989) suggested that 
the acquisition is enhanced if learning occurs in understandable and easily manageable sequences. With this in mind, Wong and Smith (2013) started research in 2009 where students were given small modular parts of classroom material for reading and learning grammar, which turned out to be a good approach in promoting m-learning.

Mobile hardware is evolving rapidly, enabling high-speed data processing and with the size and the resolution of the screen and the storage capacity increasing. Mobile phones are packed with a rich assortment of features, such as photo and video cameras, QR code reader, voice recorder, MP3 / MP4 players, internet access and the respective numerous services and social networks. As such, they are, in terms of technical characteristics, becoming comparable to personal computers. Smart phones can be easily connected to wireless networks which provide users with much greater flexibility. Some studies have shown that $\mathrm{m}$ learning has become popular among students in Korea (Park, 2012) and the United States, where the number of students opting for m-learning is on the rise, and that the majority of students in Japan prefer to download teaching materials on their mobile phones (Wang and Smith, 2013). M-learning still has certain drawbacks in comparison to e-learning, either due to technical restrictions such as small screens or the unwillingness of teachers to apply the new technologies in teaching (Franklin, 2011; Wang and Higgins, 2006.). Despite the unfavorable economic conditions in the country, the use of smart phones has become a rule rather than an exception in Croatia. Nonetheless, a study on the use of mobile devices for educational purposes in high school population has still not been conducted in Croatia. It is often the case that mobile phone use is even prohibited in the classroom.

\section{Research questions}

The aim of this study was to determine the attitudes of Croatian students of English and German towards the use of modern technologies in teaching foreign languages. The study evaluates the students' attitudes towards reading comprehension in a foreign language when using traditional methods (multiple choice questions and paper-pencil C-Test method) as opposed to solving tasks with the use of mobile technology. It also examines the level of satisfaction with ubiquitous learning and mobile learning. The question being raised is whether the characteristics of ubiquitous learning, such as the ubiquity, interactivity and autonomy, will affect the satisfaction in learning and motivation as well as the learning results.

Research Question1: Are students ready to use their mobile devices to connect, learn and create new learning experiences?

Research question 2: Do gender and type of school affect the readiness to use mobile technologies for learning purposes?

It was hypothesised that learning motivation could be improved by using online materials. User satisfaction with m-learning was presumed to be a desirable 
outcome of the study. The increased motivation due to m-learning could be an effective method for promoting reading comprehension.

\section{Research methodology}

\section{Target population and data collection}

The participants of this study were students of English and German language learning the language as their first foreign language in a high school near $\mathrm{Za}$ greb. The subjects comprised 40 high school students aged 15 and $16(n=40$, $\mathrm{m}=23, \mathrm{f}=17)$.

Table 1: Demographic Characteristics

\begin{tabular}{|l|l|c|c|}
\hline \multicolumn{2}{|c|}{ Demographic Categories } & Frequency & Percentage \\
\hline \multirow{2}{*}{ Age } & 15 & 26 & 60.5 \\
\cline { 2 - 4 } & 16 & 17 & 39.5 \\
\hline \multirow{2}{*}{ Gender } & Male & 24 & 55.8 \\
\cline { 2 - 4 } & Female & 19 & 44.2 \\
\hline \multirow{2}{*}{$\begin{array}{l}\text { Foreign } \\
\text { language }\end{array}$} & English & 21 & 48.8 \\
\cline { 2 - 4 } Type of school & German & 22 & 51.2 \\
\cline { 2 - 4 } & Grammar school & 21 & 48.8 \\
\cline { 2 - 4 } & Vocational school & 22 & 51.2 \\
\hline
\end{tabular}

Data were collected in 4 steps. Four instruments were used to collect data: a pre-study questionnaire, two reading comprehension tests and a post-study questionnaire. All participants were required to complete the pre-study questionnaire, which gathered information on the students' views on reading and on their use of the ICT.

After finishing the online test, all students were required to complete the poststudy questionnaire, which examined the students' perception of the use of mobile devices in education and their willingness to adopt new technologies.

The study examined the subjects' perception of the use of technology for educational purposes using two questionnaires and two reading comprehension tests in English and in German. The first questionnaire collected information on the perception of reading, the reading habits, and the ways of using technology in leisure time and in the school context. The students were also required to give an estimate of the extent to which technology is used for education purposes in their school.

The subjects were asked to indicate the extent to which they agreed with the items on a Likert scale, with the options ranging from "strongly disagree" to "strongly agree", and from "never" to "always". After that, two reading comprehension tests were conducted. The instrument used were standardized tests of the basic A2 level of the state graduation exam, which is also the level of knowledge required by the curriculum from students in the first year of the secondary education. 
The first of the two tests was carried out as a conventional paper-pencil test during the same class period in which the students filled out the questionnaire A, while the second test was to be filled out using one's mobile phone within 24-hours from accessing the test. The access was enabled via an application which was developed for the purpose of the study and made available for download on the school website. It was protected by a password and available only to the subjects of the study. The students had to answer all the questions before they could receive feedback. They were encouraged to study the feedback, re-read the material, identify errors themselves and then change any answers which they thought were incorrect. After the second test, the students filled out the questionnaire 2 in the next class period. The questionnaire examined the students' perception of completing the test in the conventional way as opposed to the online test as well as the motivation for the use of mobile technology in learning and how useful did they find the received feedback for the process of learning.

The study was more of an exploratory than confirmatory nature, since the subjects used their mobile phones to complete a test for school purposes for the first time. The chosen type of interaction for this study was the one in which the student's performance is followed by a computer-generated feedback. Such feedback came from instructional materials containing explicit exercises aimed at providing learners with practice in particular areas of reading, grammar and vocabulary. The learners were provided with immediate feedback on the correctness of their responses to the questions.

\section{Results}

The study investigated the students' perception of the use of mobile learning in education. The SPSS program was used in the data analysis. The analysis of the collected data showed that online reading and solving a test using mobile phones is considered to be a positive experience. The enjoyment of using a mobile device had a positive effect on the students' attitudes and improved learning motivation can improve performance.

The analysis of data gathered from subjects, shown in Figure 1 showed that only a small part of the subjects state that reading is their favorite activity. In relation to that, most of them read a maximum of 60 minutes a day and one book a month.

Unlike reading, the Internet is a favorite activity. Students spend 1 or 2 hours online every day, without significant differences between working days and weekends, except in the category of more than four hours a day, as evident in Figure 2.

After the online test, students' attitudes towards the type of test were expressed by the second questionnaire. Although most participants considered the online test more interesting and less stressful, as evident in Figure 3, they would still prefer to write the next test in the classical way. 


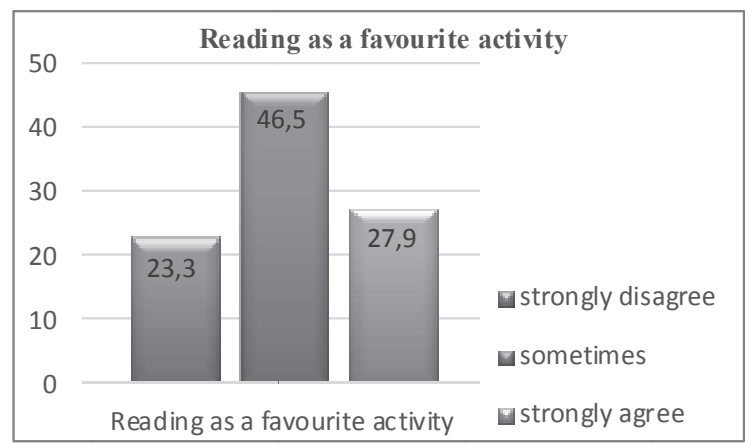

Figure 1: Reading as a favorite activity

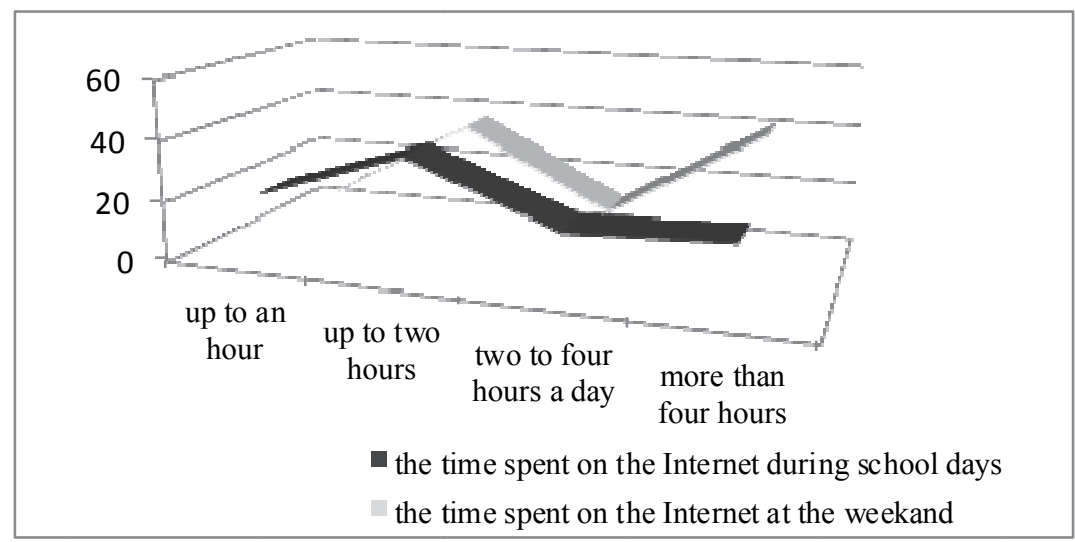

Figure 2: Time spent on the Internet

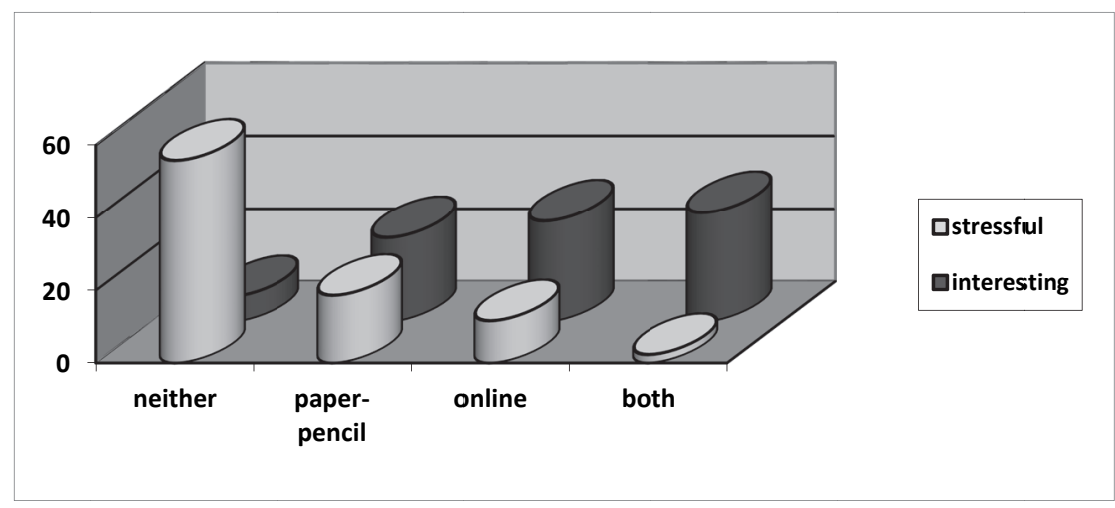

Figure 3: Attitudes towards the type of test 
We received a positive response to the first research question. The students were motivated to solve the online test so it is somewhat surprising that in the future they would prefer to write tests in paper-pencil method.

The response to the second research question shows a significant difference between students of different gender and between students attending a different type of school. Female students mainly opt for the grammar school, while male students opt for the vocational school. A significant difference has also been identified between students of different gender and between students attending a different type of school with respect to reading, which is a far more popular activity among grammar school students, i.e. female students. However, no statistically significant correlation has been found between these two variables (gender and the type of school) and the age at which students first used computers and the attitudes towards the use of computers and the Internet for school and learning. A statistically significant difference has been found between the type of school and the attitude towards future testing: although grammar school students found the online test more interesting and less stressful, they would still prefer to take the next test in the paper-pencil method, unlike vocational school students who would prefer to be tested online.

Table 2: Correlations between Constructs

\begin{tabular}{|c|c|c|c|c|c|c|c|}
\hline Variables & (1) & $(2)$ & (3) & (4) & (5) & (6) & (7) \\
\hline (1) Gender & 1 & & & & & & \\
\hline (2) Type of the school &,$- 682 * *$ & 1 & & & & & \\
\hline $\begin{array}{l}\text { (3) Reading as a } \\
\text { favorite activity }\end{array}$ &, $468 * *$ &,$- 453 * *$ & 1 & & & & \\
\hline $\begin{array}{l}\text { (4) The age of the first } \\
\text { Internet use }\end{array}$ &, 142 &,- 143 &, $373 *$ & 1 & & & \\
\hline $\begin{array}{l}\text { (5) Attitudes about } \\
\text { Internet for school }\end{array}$ &, 047 &,- 120 &, 090 &,- 265 & 1 & & \\
\hline $\begin{array}{l}\text { (6) Online test was } \\
\text { more interesting }\end{array}$ &,- 091 &, 041 &, 065 & ,095 &,- 103 & 1 & \\
\hline $\begin{array}{l}\text { (7) I want to take the } \\
\text { next test online }\end{array}$ &,- 283 &, $351 *$ & ,214 &,- 002 &,- 172 & ,395 & 1 \\
\hline
\end{tabular}

$*: p<0.05 ;{ }^{* *}: p<0.01$

\section{Conclusion}

The findings of this study suggest that mobile technologies have the potential to provide new learning experiences. Students can engage in learning activities outside the classroom, at any time and any location. Although many teachers already use technology in their classes, the results have shown that the ICT is not used often, even in well-equipped schools (in only 40 out of 1800 class periods held in a school year). Mobile learning requires a certain level of technological knowledge, which could be the reason for a lack of readiness of teachers to adopt this method of learning and teaching. Although the use of mobile devices is ubiquitous, the students have not shown readiness for mobile learning. 
The reason for this could be the fact that, in comparison to PC's, mobile phone screen size is much smaller.

\section{Limitations and future work}

The number of subjects was small $(\mathrm{N}=43)$, so the findings cannot be generalized. For further research the student sample should be gathered from different schools and possibly compared with the fourth class to see whether it the age affects the attitudes about m-learning. It would also be interesting to examine whether students' readiness for mobile learning increases if, instead in testing, mobile devices are used, in group work and other collaborative activities which provide opportunities for student interaction so the communication features of smartphones could be used in the best possible way.

\section{References}

Chen, C.-M., Hsu, S.-H. Personalized Intelligent Mobile Learning System for Supporting Effective English Learning. //Educational Technology \& Society, 11(2008), 3; 153-180

Dohmen, G. Das informelle Lernen. Die internationale Erschließung einer bisher vernachlässigten Grundform menschlichen Lernens für das lebenslange Lernen aller. Bonn: Bundesministerium für Bildung und Forschung, 2001

Europäische Kommision: Weißbuch: Lehren und Lernen. Auf dem Weg zur kognitiven Gesellschaft, Brüssel, 1995

Franklin, T. MOBILE LEARNING: AT THE TIPPING POINT. // The Turkish Online Journal of Educational Technology, Vol.10 (2011), 4: 261-275

Heift, T. and Chapelle, C.A. Language learning through technology. // Gass, S.M. and Mackey, A. (Eds.), The Routledge Handbook of Second Language Acquisition (pp.555 - 569). New York: Routledge, 2012

$\mathrm{Hu}, \mathrm{Z}$. Vocabulary Learning Assisted by Mobile Phones: Perceptions of Chinese Adult Learners. In Journal of Cambridge Studies, Vol. 8 (2013), No. 1; 139 - 154

Jung, H.-J. Ubiquitous Learning: Determinants impacting Learnerns' Satisfaction and Performance with Smartphones. // Language Learning and Technology, 18(2014), 3; 97-119

Kim, D., Rueckert, D., Kim, D.-J., Seo, D. Students' perceptions and experiences of mobile learning. // Language Learning and Technology, Vol. 17 (2013), 3; 52-73.

Krashen, S. We acquire vocabulary and spelling by reading. Additional evidence for the input hypothesis. // Modern Language Journal, 73 (1989); 440-464

Liaw, M.- L. E-Learning and the Development of interculturale competence. // Language Learning \& Technology, Vol. 10 (2006), 3; 49-63.

Lipinski, J. Lernen und Interesse. München Deutsches Jugendinstitut (DJI): Informeles Lernen in der Freizeit. Erste Ergebnisse des Projekts "Lebenswelten als Lernwelten", 2000

$\mathrm{Lu}, \mathrm{M}$. Effectiveness of vocabulary learning via mobile phone. // Journal of Computer Assisted Learning, 24 (2008), 6; 515-525

O'Malley, C, Vavoula, G., Glew, J., Taylor, J., Sharples, M., Lefrere, P. (2003). Guidelines for learning / teaching / tutoring in a mobile environment. Mobilearn project deliverable. 201504-11. https://hal.archives-ouvertes.fr/hal-00696244/document

Park, S. Y., Nam, M.-W, Cha, S.-B. University students' behavioral intention to use mobile learning: Evaluating the technology acceptance model. // British Journal of Educational Technology, Vol. 43 (2012), 4; 592-605.

Petrova, K., Li, C. Focus and Setting in Mobile Learning Research: A Review of the Literature. // Communications of the IBIMA, Vol.10 (2009); 219-226 
Roreger, H., Schmidt, T.C. Mobiles Lernen im Zeitalter sozialer Medien. In Schulz, M. and Neusius, A. (Eds.), Grundlagen der Weiterbildung. Hergensweiler: ZIEL-Verlag, 2012

Specht, M., Ebner, M. Mobiles und ubituitëres Lernen. Technologien und didaktische Aspekte. In Ebner, M. and Schön, S. (Eds.), Lehrbuch für Lernen un Lehren mit Technologien. Berlin, 2011

Stockwell, G. Using mobile phones for vocabulary activities: Examining the effect of the platform. // Language Learning \& Technology, Vol. 14 (2010), 2; 95 - 110

Wang, S., Higgins, M. Limitations of Mobile Phone Learning. // The JALT CALL Journal, Vol.2, (2006) No.1; 3-14

Wang, S., Smith, S. Reading and grammar learning through mobile phones. // Language Learning and Technology, 17 (2013), 3; 117-134 